\title{
On the Use of a $\mathrm{TiO}_{2}$ Sol-Gel for Horseradish Peroxidase Enzyme Immobilization for Development of an Amperometric Biosensor
}

\author{
Carolina G. da Rocha, ${ }^{\circledR a}$ Carolina V. Uliana ${ }^{\circledR a}$ and Hideko Yamanaka ${ }^{* a}$ \\ ${ }^{a}$ Departamento de Química Analítica, Físico-Química e Inorgânica, Instituto de Química, \\ Universidade Estadual Paulista (Unesp), Rua Professor Francisco Degni 55, \\ 14800-060 Araraquara-SP, Brazil
}

\begin{abstract}
The sol-gel technique has drawn considerable attention in the area of biomolecules immobilization by virtue of its intrinsic properties including chemical inertness, thermal stability, and good biocompatibility. The present work reports the development of a bio-sensing methodology which involves the immobilization of horseradish peroxidase enzyme (HRP) on pencil graphite electrode (PGE) using $\mathrm{TiO}_{2}$ sol-gel and its application for 5-aminosalicylic acid (5-ASA) determination in pharmaceutical formulations. $\mathrm{TiO}_{2}$ sol-gel film was deposited on the PGE surface by dip coating, and the HRP enzyme was immobilized on the film by adsorption and cross-linked binding using glutaraldehyde. The analytical performance of the methodology was investigated through amperometric measurements at $-0.08 \mathrm{~V}$ in the presence of 5-ASA (electron mediator) and hydrogen peroxide (substrate). The biosensor was successfully applied for 5-ASA determination, where limits of detection and quantification of 3.3 and $10.0 \mu \mathrm{mol} \mathrm{L}^{-1}$, respectively, were obtained. The application of the methodology for 5-ASA determination in pharmaceutical formulations led to satisfactory recovery rates ranging from 80 to $98 \%$. The biosensor developed in this work is simple, inexpensive and has the potential to be applied for the determination of other pharmaceutical compounds, which also act as electron mediators in the catalytic cycle of HRP.
\end{abstract}

Keywords: $\mathrm{HRP}$ enzyme, $\mathrm{TiO}_{2}$ sol-gel, pencil graphite electrode, 5-aminosalicylic acid

\section{Introduction}

Horseradish peroxidase (HRP) (EC 1.11.1.7) belongs to the superfamily of heme-containing plant peroxidases, which promotes the bioelectrocatalytic reduction of $\mathrm{H}_{2} \mathrm{O}_{2}$ and the oxidation of organic and inorganic substrates; although there a great variety of peroxidases, HRP is undoubtedly the most commonly used in practical analytical applications. Besides that, HRP retains its activity over a broad range of $\mathrm{pH}$ and temperature, which facilitate its use. ${ }^{1}$ In fact, this enzyme has been used for a wide range of purposes in environmental (e.g., wastewater remediation) and biological areas (e.g., electrochemical biosensors)..$^{2-5}$ Electrochemical biosensors offer a great potential for HRP application due to the possibility of combining its high stability, selectivity and sensitivity in low cost chemical analysis methods. Despite their seemingly unstable and delicate structures, enzymes can be resistant like any other chemical catalyst if used properly. ${ }^{6}$ However, it is worth noting that one needs to obtain an efficient interface

*e-mail: hideko.yamanaka@unesp.br between the biomolecule and the electronic transducers in order to ensure an effective immobilization of the enzymes on the surfaces of electrodes. When they are bound to an inert support material, bioactive molecules may be rendered insoluble, retaining their catalytic activity, thereby extending their useful life. ${ }^{7}$

A wide range of electrode materials have been used as platforms for HRP immobilization; among these materials, those that have been most commonly used include glassy carbon, ${ }^{8-10}$ glassy carbon modified with carbon nanotube, ${ }^{11-13}$ gold, ${ }^{14-16}$ carbon paste, ${ }^{17-19}$ and platinum. ${ }^{20-22}$ Over the last decades, pencil graphite-based devices have also been employed as platforms for the construction of biosensors. ${ }^{23}$ Since the quality of pencil graphite is highly controlled in the manufacturing process, there are rare differences in electrochemical behavior among different pencil graphite electrodes. In addition, pencil graphite electrodes (PGEs) are not as fragile as carbon paste electrodes (CPEs), and they are not as rigid as glassy carbon electrodes (GCEs). Thus, compared to other carbon materials, PGEs are superior in terms of mechanical properties and handling. Considering that pencil graphite is extremely cheap 
and widely abundant, PGEs can be used as disposable electrodes ${ }^{24,25}$ and have been successfully applied toward the immobilization of deoxyribonucleic acid (DNA), ${ }^{26-28}$ antibody, ${ }^{29-31}$ and enzymes ${ }^{32-34}$ in the construction of electrochemical biosensors.

Several techniques involving HRP immobilization on electrode materials have been described in the literature, ${ }^{35-38}$ these techniques include physical adsorption, covalent attachment, electrostatic interactions and entrapment on polymerized films. Specifically, the sol-gel technique has been widely employed for the immobilization of a variety of biomolecules because of its special properties, which include simplicity of preparation, chemical inertness, physical rigidity, high-thermal stability, biodegradation, and optical transparency. ${ }^{39-41}$ Essentially, the major advantage of a sol-gel system lies in its ability to retain a large content of water. This outstanding property helps ensure a long-term stability for the encapsulated bio-recognition agents or enzyme catalytic centers; apart from that, the process can be performed at room temperature. Other remarkable advantages of the sol-gel system include its biocompatibility and resistance to microbial attack. ${ }^{7}$

$\mathrm{TiO}_{2}$ sol-gel based biosensors have been previously employed for the immobilization of different types of enzymes. ${ }^{42-44}$ In comparison to $\mathrm{SiO}_{2}$ or $\mathrm{Al}_{2} \mathrm{O}_{3}$ sol-gel based immobilization matrices, $\mathrm{TiO}_{2}$ presents good biocompatibility, since the titanium coordinates with amine and carboxyl groups present in the enzyme. This intrinsic property of $\mathrm{TiO}_{2}$ is regarded highly beneficial for both the immobilization of enzymes and the maintenance of bioactivity of the system, and thus contributes toward improving the biosensor performance. Titanium colloidal suspensions can be easily produced by hydrolysis of titanium alkoxides; as such, they are regarded viable alternative substrates for HRP immobilization. ${ }^{45,46}$

5-Aminosalicylic acid (5-ASA, mesalazine, CAS 89-57-6) is widely used for the treatment of inflammatory bowel diseases (IBDs), especially for ulcerative colitis and Crohn's disease. ${ }^{47,48}$ The mesalazine action is uncertain but probably occurs by inhibition of prostaglandin and leukotriene synthesis in the gastrointestinal mucosa. ${ }^{49}$ The levels of 5-ASA in pharmaceutical formulations have been traditionally quantified by using chromatographic techniques. Although routinely used, these techniques are relatively expansive and not free of drawbacks since they can often include labor-intensive sample preparation and extended analysis time. In this way, electroanalytical techniques have been also proposed for 5-ASA determination, which contributed for developing a cheaper and more rapid analysis. $^{50}$
In a previous work reported in the literature, ${ }^{51}$ the authors of the present work investigated the electrochemical behavior of HRP in solution in the presence of hydrogen peroxide and 5-aminosalycilic acid (5-ASA) (employed as electron mediator). In another study ${ }^{50}$ that deserves mentioning, pencil graphite was used for the determination of 5-ASA in commercial medicine. Based on the findings of the aforementioned studies, ${ }^{50,51}$ the present work sought to apply HRP as a model for enzyme immobilization on pencil graphite electrodes (PGE) using $\mathrm{TiO}_{2}$ sol-gel. Thus, the central goal of the study was to develop a novel, simple, effective and low-cost HRP immobilization methodology using $\mathrm{TiO}_{2}$ sol-gel modified pencil graphite electrodes (PGEs). The methodology was applied for the determination of 5-ASA in commercial pharmaceutical formulations.

\section{Experimental}

\section{Reagents and solutions}

Monobasic sodium phosphate, dibasic sodium phosphate, $25 \%$ glutaraldehyde $(\mathrm{v} / \mathrm{v}), 30 \%$ hydrogen peroxide $(\mathrm{m} / \mathrm{m})$, horseradish peroxidase enzyme (EC 1.11.1.7, $1500 \mathrm{U} \mathrm{mg}^{-1}$ ) and titanium(IV) isopropoxide were acquired from SigmaAldrich (Saint Louis, USA). Monohydrate citric acid and potassium chloride were obtained from Mallinckrodt (Phillipsburg, USA). 5-Aminosalicylic acid (5-ASA) was obtained from Acros (Geel, Belgium).

HRP was dissolved in deionized water $\left(1.0 \mathrm{mg} \mathrm{mL}^{-1}\right)$. Solution of $1 \%$ glutaraldehyde was prepared in $0.1 \mathrm{~mol} \mathrm{~L}^{-1}$ phosphate buffer ( $\mathrm{pH} 7.0$ ). All solutions were stored in a freezer at $-4{ }^{\circ} \mathrm{C}$. Enzymatic activity was monitored using $\mathrm{H}_{2} \mathrm{O}_{2}$ as substrate and 5-ASA as electron mediator. 0.07 mol L-1 $\mathrm{H}_{2} \mathrm{O}_{2}$ stock solutions were prepared immediately before use. 5-ASA aqueous stock solutions $\left(1.0 \times 10^{-3} \mathrm{~mol} \mathrm{~L}^{-1}\right)$ were prepared by dissolving the pure powder in phosphate-citrate buffer at $\mathrm{pH}$ 5.0, and heating the solution at a temperature of $60^{\circ} \mathrm{C}$ for $5 \mathrm{~min}$ in order to obtain a complete dissolution of the compounds. A $0.1 \mathrm{~mol} \mathrm{~L}^{-1}$ phosphate-citrate buffer solution at $\mathrm{pH} 5.0$ was used as the supporting electrolyte. The solutions were prepared using high-purity water (resistivity $(\rho)=18.2 \mathrm{M} \Omega \mathrm{cm}$ ).

$\mathrm{TiO}_{2}$ sol-gel was prepared by adding titanium(IV) isopropoxide $(20 \mathrm{~mL})$ to a solution of nitric acid in deionized water in order to obtain a resultant solution of $\mathrm{Ti}: \mathrm{H}^{+}: \mathrm{H}_{2} \mathrm{O}$ in a molar ratio of 1:0.5:200 (v/v/v). The precipitate obtained was continuously stirred until complete peptization in order to produce a stable suspension, which was dialyzed in deionized water up to $\mathrm{pH} 3.5$, using a Micropore (3500 MW) dialysis membrane..$^{52,53}$ 
Instrumentation

Type-HB (Faber-Castell) pencil leads with a total length of $60 \mathrm{~mm}$ and a diameter of $0.9 \mathrm{~mm}$ were obtained from a local bookstore. Initially, the bare pencil leads were cleaned with absorbent paper to remove any particles on the surface and the working area was established (delimiting the boundaries) by wrapping a sealing film (Parafilm M) around the pencil lead at a height of $3.0 \mathrm{~mm}$ from the top; the working area covered a geometric area of $0.091 \mathrm{~cm}^{2}$ of the PGE. The other end of the PGE was directly connected to the equipment. Each experiment was performed using a new PGE. Amperometric measurements were performed in $0.1 \mathrm{~mol} \mathrm{~L}^{-1}$ citrate-phosphate buffer (at $\mathrm{pH}$ 5.0) containing $5.0 \times 10^{-4} \mathrm{~mol} \mathrm{~L}^{-1} 5$-ASA and $3.5 \times 10^{-3} \mathrm{~mol} \mathrm{~L}^{-1} \mathrm{H}_{2} \mathrm{O}_{2}$, using an EG\&G-PAR model 263 (Maryland, USA) computer-controlled potentiostat. A $5.0 \mathrm{~mL}$ one-compartment cell which consisted of a threeelectrode system was employed. The three-electrode system was composed of a PGE working electrode, a $\mathrm{Agl} \mathrm{AgCl}\left(\mathrm{KCl}_{\text {sat }}\right)$ reference electrode, and a platinum wire auxiliary electrode. The morphological characterization of the modified PGE was conducted via high resolution scanning electron microscopy with a field emission gun (SEM-FEG, field emission scanning electron microscope, Jeol (Tokyo, Japan), Model JSM7500). The sol-gel films were deposited on the surface of the PGE by dip coating (Microquímica MQCTL2000-MP, Palhoça, Brazil); this involved $1 \mathrm{dip}$ at a lifting speed of $100 \mathrm{~mm} \mathrm{~min}^{-1}$.

\section{Electrode modification}

Figure 1 summarizes the steps involving PGE modification for the immobilization of HRP and detection of 5-ASA. Initially, sol-gel films were deposited on a clean PGE surface by dip coating (Figures 1a-1b). All the electrodes were allowed to dry at room temperature for $24 \mathrm{~h}$ after deposition. Next, the PGE was sequentially immersed in glutaraldehyde (Figure 1c) and HRP solutions (Figure 1d). In between the modification steps, the electrodes were thoroughly washed in $0.1 \mathrm{~mol} \mathrm{~L}^{-1}$ phosphate buffer solution (at $\mathrm{pH}$ 7.0) in order to remove any weakly attached molecules on the electrode surface. Finally, amperometric measurements were performed in the presence of a fixed concentration of $\mathrm{H}_{2} \mathrm{O}_{2}$ (substrate) and different concentrations of 5-ASA (electron mediator) (Figure 1e). The appearance of the anodic peak current was associated with the reduction of 5-ASA $\mathrm{Ax}_{\text {g }}$ generated during the HRP enzymatic process.

To obtain the experimental conditions with the best analytical signal, a two-level-three-factor $\left(2^{3}\right)$ full factorial experiment was developed. A full factorial design can be represented by $b^{\mathrm{k}}$, where $\mathrm{k}$ is the number of factors (or variables), and $b$ is the chosen number of levels. Factorial designs with two levels $\left(2^{\mathrm{k}}\right)$ have been the most commonly used for the development of biosensors; experiments conducted using two-level factorial designs are found to be more efficient than those that investigate one factor at a time. ${ }^{52,53}$ In this work, the following factors were evaluated: (i) incubation time of the electrodes in HRP solution $\left(\mathrm{t}_{\mathrm{HRP}}\right)$; (ii) glutaraldehyde concentration $\left(\mathrm{C}_{\mathrm{glu}}\right)$; and (iii) incubation time of the electrodes in glutaraldehyde solution $\left(\mathrm{t}_{\mathrm{glu}}\right)$. The values chosen for the high and low levels of factors are presented in Table 1. The electrochemical conditions and the concentrations of $\mathrm{H}_{2} \mathrm{O}_{2}$ and 5-ASA in the electrochemical cell were kept constant under the different combined sets of conditions $\left(3.5 \times 10^{-3} \mathrm{~mol} \mathrm{~L}^{-1}\right.$ of $\mathrm{H}_{2} \mathrm{O}_{2}$ and $2.0 \times 10^{-4} \mathrm{~mol} \mathrm{~L}^{-1}$ of 5-ASA); this was done with the exclusive goal of determining the influence of the factors investigated in the system. Minitab 15 software $^{54}$ was used to generate the sequence and the combined set of experimental conditions for performing the assays, as well as for the analysis of the signal obtained (current intensity, $-\mathrm{I} / \mu \mathrm{A})$. The magnitude of the influence of each factor on the analytical signal was determined. ${ }^{55,56}$ The optimized conditions obtained from the full factorial design analysis were adopted for the subsequent experiments.

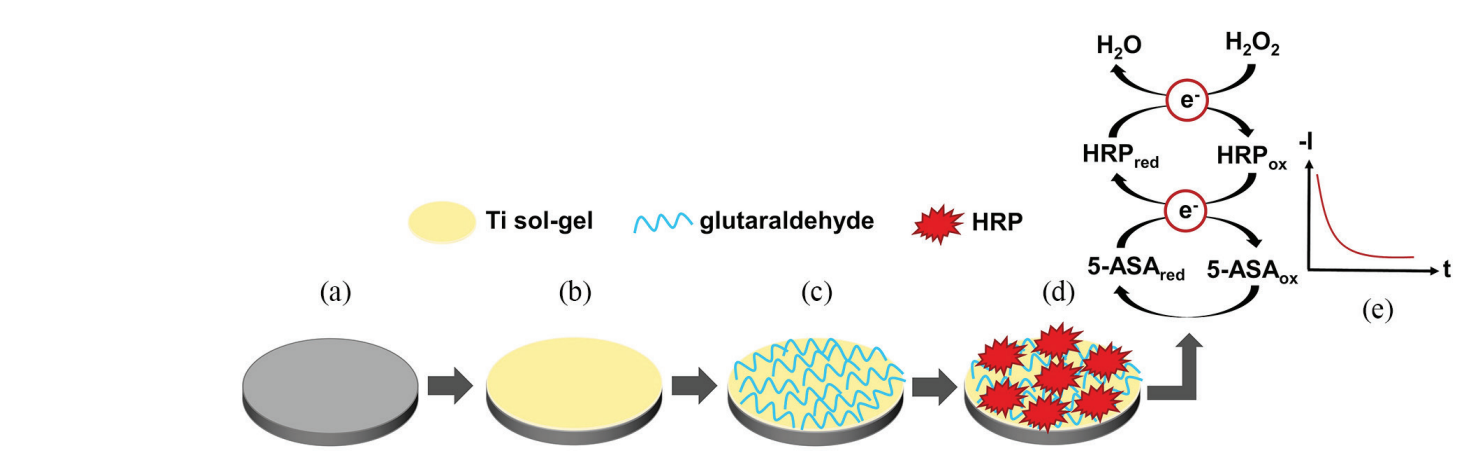

Figure 1. Schematic illustration of PGE modification with HRP immobilization and 5-ASA detection: (a) bare PGE, (b) deposition of TiO ${ }_{2}$ sol-gel film, (c) incubation in the glutaraldehyde solution, (d) HRP immobilization and (e) amperometric measurements in the presence of 5- $\mathrm{ASA}^{-}$and $\mathrm{H}_{2} \mathrm{O}_{2}$. 
Table 1. High and low levels of the factors evaluated in a $2^{3}$ full factorial design used for the optimization of HRP immobilization on the surface of PGE

\begin{tabular}{lcc}
\hline Factor & High level & Low level \\
\hline Glutaraldehyde concentration $\left(\mathrm{C}_{\mathrm{glu}}\right) / \%(\mathrm{v} / \mathrm{v})$ & 1.0 & 0.1 \\
Glutaraldehyde incubation time $\left(\mathrm{t}_{\mathrm{glu}}\right) / \mathrm{h}$ & 2 & 1 \\
HRP incubation time $\left(\mathrm{t}_{\mathrm{HRP}}\right) / \mathrm{h}$ & 2 & 1 \\
\hline
\end{tabular}

HRP: horseradish peroxidase enzyme.

\section{5-ASA analysis in commercial pharmaceutical formulations}

Calibration curves $(n=3)$ were obtained by spiking known concentrations of 5-ASA to the electrolytic cell containing $5.0 \mathrm{~mL}$ of $0.1 \mathrm{~mol} \mathrm{~L}^{-1}$ citrate-phosphate buffer solution (at pH 5.0) and $3.5 \times 10^{-3} \mathrm{~mol} \mathrm{~L}^{-1} \mathrm{H}_{2} \mathrm{O}_{2}$. The limit of detection (LOD) and the limit of quantification (LOQ) were calculated based on the following equations: $\mathrm{LOD}=3 \times \mathrm{sd} / \mathrm{B}$ and $\mathrm{LOQ}=10 \times \mathrm{sd} / \mathrm{B}$, respectively; where sd is the standard deviation of the average value of the currents obtained for ten blank solutions, and B is the slope of the analytical curve.

Recovery experiments were conducted by adding a known concentration of the target compound to the electrolytic cell containing $5.0 \mathrm{~mL}$ of $0.1 \mathrm{~mol} \mathrm{~L}^{-1}$ citratephosphate buffer (at pH 5.0) and $3.5 \times 10^{-3} \mathrm{~mol} \mathrm{~L}^{-1} \mathrm{H}_{2} \mathrm{O}_{2}$. The current intensities obtained were directly interpolated in the linear regression equation from the 5-ASA analytical curve, and the concentrations were determined. All measurements were performed in triplicate. The recovery efficiencies $(\mathrm{R}$, in percentage) were calculated based on the following equation: $\mathrm{R}(\%)=(([5-\mathrm{ASA}]$ obtained/[5-ASA] added $) \times 100)$, where the value of "[5-ASA] obtained" refers to the concentration obtained by interpolation in the corresponding curve.

The proposed methodology was applied for the determination of 5-ASA in commercial medicinal tablets and enemas. For pharmaceutical formulations in tablets,

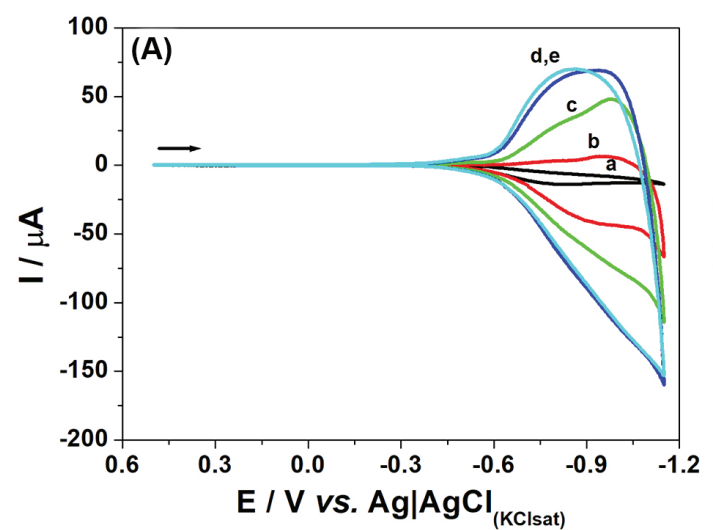

the Brazilian Pharmacopeia recommends weighing twenty tablets and powdering them. ${ }^{57}$ Taking into account the 5-ASA content labeled in the commercial sample formulations, sample solutions of $1.0 \times 10^{-3} \mathrm{~mol} \mathrm{~L}^{-1} 5$-ASA were prepared in deionized water by heating at $60{ }^{\circ} \mathrm{C}$ for $5 \mathrm{~min}$. Aliquots of the sample solution corresponding to $5.0 \times 10^{-5} \mathrm{~mol} \mathrm{~L}^{-1}$ were transferred to the electrochemical cell containing $5.0 \mathrm{~mL}$ of the supporting electrolyte and $3.5 \times 10^{-3} \mathrm{~mol} \mathrm{~L}^{-1}$ of $\mathrm{H}_{2} \mathrm{O}_{2}$, and the amperograms were recorded.

\section{Results and Discussion}

Deposition of $\mathrm{TiO}_{2}$ sol-gel film on the surface of PGE

The number of sol-gel film depositions on PGE surface was monitored by cyclic voltammetry in the range of $+0.5 \mathrm{~V}$ to $-1.15 \mathrm{~V} v s$. $\mathrm{AglAgCl}\left(\mathrm{KCl}_{\text {sat }}\right)$, at scan rate of $50 \mathrm{mV} \mathrm{s}^{-1}$ using $0.1 \mathrm{~mol} \mathrm{~L}^{-1}$ phosphate buffer solution of $\mathrm{pH} 7.0$ (Figure 2A). The current intensities at the potential around $-0.9 \mathrm{~V}$ in both direct and reverse scans increased as the number of sol-gel film depositions increased up to 4 depositions. No significant changes were observed after the fourth deposition onwards. This behavior is associated with the reduction of $\mathrm{Ti}^{\mathrm{IV}}$ to $\mathrm{Ti}^{\mathrm{III}}$ and the electrons conduction through the oxide. ${ }^{58}$ The voltammetric responses observed were found to be typically characteristic of $\mathrm{TiO}_{2}$ thin films; this has been associated with sequential filling of electron states within the oxide. ${ }^{59}$

To evaluate the influence of the deposition of solgel film on the response of $\mathrm{K}_{4} \mathrm{Fe}(\mathrm{CN})_{6}$ on PGEs, cyclic voltammograms were recorded in the range of $-0.3 \mathrm{~V}$ to $+0.7 \mathrm{~V}$, at scan rate of $50 \mathrm{mV} \mathrm{s}^{-1}$, using $1.0 \times 10^{-2} \mathrm{~mol} \mathrm{~L}^{-1}$ $\mathrm{K}_{4} \mathrm{Fe}(\mathrm{CN})_{6}$ solution after a varied number of (sol-gel film) depositions (Figure 2B). As can be noted, a significant decrease was observed in the anodic and cathodic peak current intensities as the number of depositions increased.

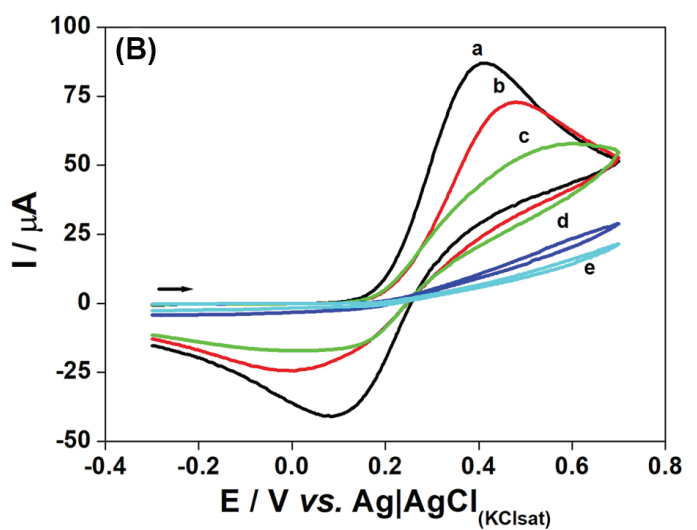

Figure 2. Cyclic voltammograms performed in (A) phosphate buffer at $\mathrm{pH} 7.0$ and (B) $1.0 \times 10^{-2} \mathrm{~mol} \mathrm{~L}^{-1} \mathrm{~K}_{4} \mathrm{Fe}(\mathrm{CN})_{6}$ solution using PGE after TiO${ }_{2}$ sol-gel deposition of (a) 0; (b) 1; (c) 2; (d) 3 and (e) 4 sol-gel film layers. 
This behavior suggests that, as the gel thickness increases, the diffusion of the analyte from the solution to the electrode is undermined, and this leads to the decay of the electrochemical signal. Thus, only one sol-gel film deposition (the first deposition) was chosen for conducting all experiments.

The morphological characterization of the sol-gel film deposition on the PGE surface was performed by SEM-FEG. Figures $3 \mathrm{a}$ and $3 \mathrm{c}$ show the typical ripple and porous morphology of the bare PGE, subjected to 100and 500-times magnification, respectively. Longitudinal grooves are present in the entire extension of the bare PGE surface as a result of the production process of pencil leads. Figures $3 b$ and $3 d$ are related to the images obtained for the PGE coated with $\mathrm{TiO}_{2}$ sol-gel film (PGE/sol-gel), subjected to 100- and 500-times magnification. Based on these images, one can observe the presence of a brittle film covering the entire PGE surface; this is attributed to the $\mathrm{TiO}_{2}$ sol-gel film. The regions that are completely covered on the PGE provide a stable platform for HRP immobilization; this occurs through the glutaraldehyde over the sol-gel base. By contrast, the cracked regions in the film provide a viable way for electron transfer between the mediator and the electrode.

\section{HRP electrochemical response}

For most of the materials employed in electrode modification, direct electron transfer between the materials and HRP enzyme is known to be a kinetically slow process. To solve this sluggish heterogeneous electron transfer problem, one particularly attractive approach reported in the literature involves the use of an electron mediator, a lowmolecular weight molecule, which facilitates the electron transfer between an oxidoreductase enzyme active site and a working electrode material. ${ }^{60}$

In the present work, the biosensor analytical signal is derived from the electrochemical behavior of the HRP enzyme in the presence of $\mathrm{H}_{2} \mathrm{O}_{2}$ (substrate) and 5-ASA (electron mediator). ${ }^{51}$ To evaluate the potential for enzymatic reaction involving 5-ASA, cyclic voltammetry measurements were performed using the PGE containing one sol-gel film layer, in the range of +0.30 to $-0.30 \mathrm{~V}$, at scan rate of $50 \mathrm{mV} \mathrm{s}^{-1}$, in phosphate-citrate buffer (at $\mathrm{pH} 5.0$ ) containing $3.5 \times 10^{-3} \mathrm{~mol} \mathrm{~L}^{-1} \mathrm{H}_{2} \mathrm{O}_{2}$ and $5.0 \times 10^{-4} \mathrm{~mol} \mathrm{~L}^{-1}$ 5-ASA, in the absence and presence of $0.1 \mathrm{mg} \mathrm{mL}^{-1} \mathrm{HRP}$ in solution (Figure 4).

There was a significant increase in current intensity at $-0.08 \mathrm{~V}$ in the presence of HRP. This result suggests that 5-ASA is oxidized by HRP in the presence of $\mathrm{H}_{2} \mathrm{O}_{2}$; and
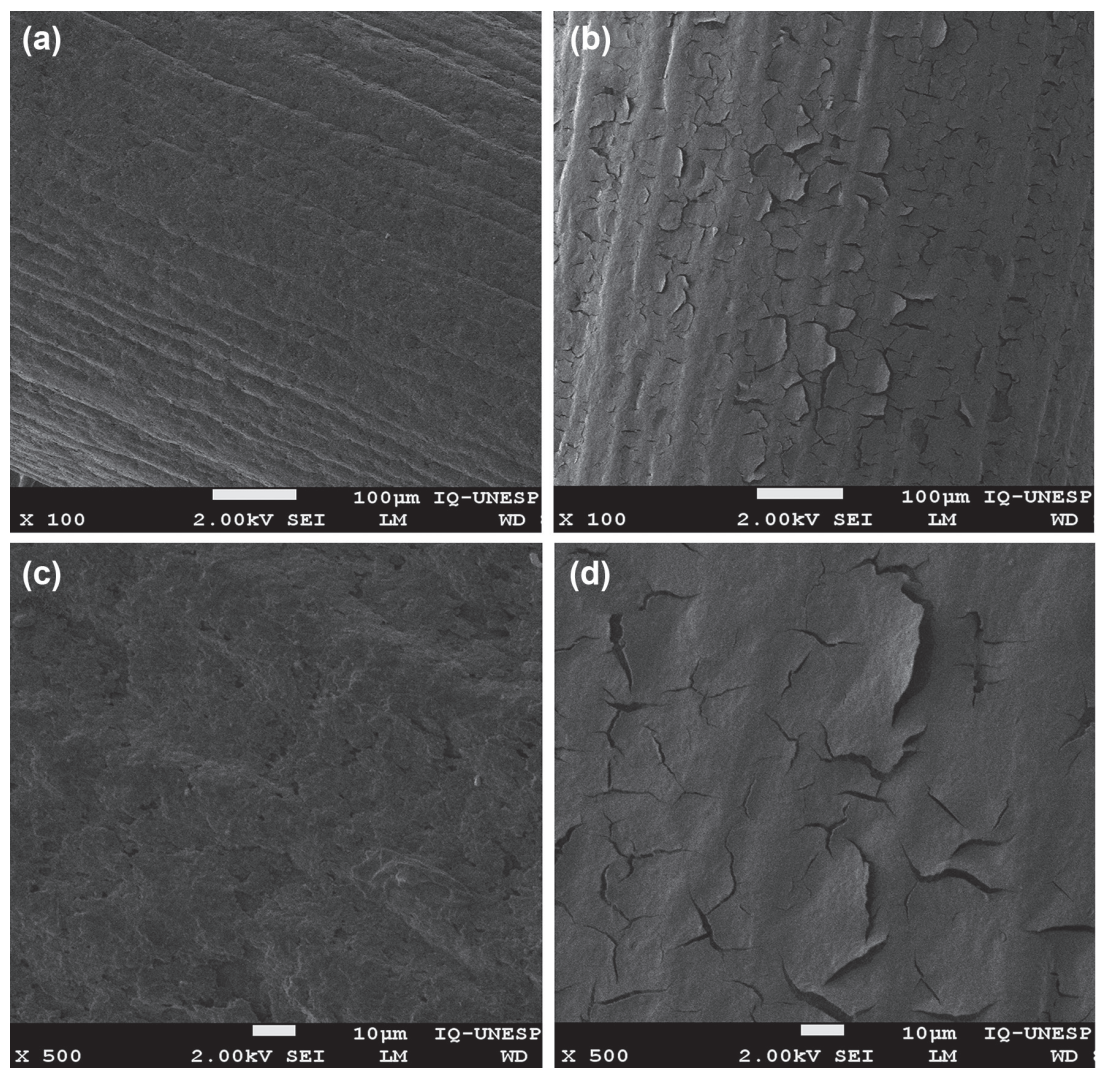

Figure 3. SEM-FEG images of the bare PGE (a) and (c), subjected to 100- and 500-times magnification, respectively. Images (b) and (d) are related to the modified PGE (PGE/sol-gel), subjected to the same magnification rates. 


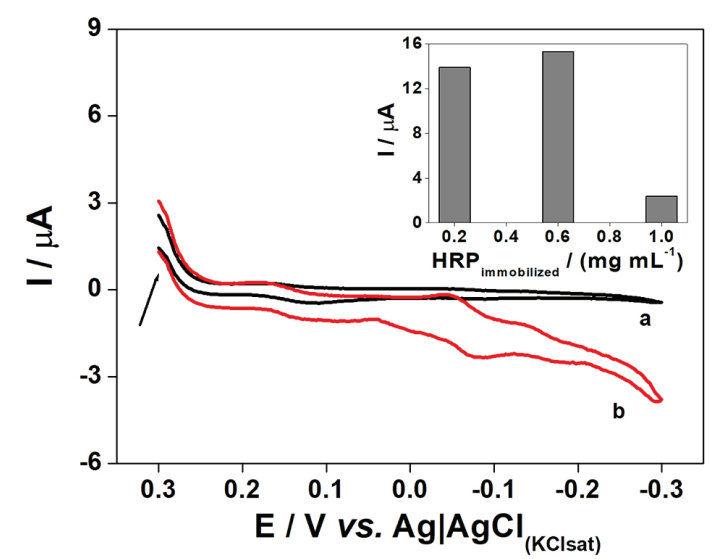

Figure 4. Cyclic voltammograms for the application of PGE/sol-gel in phosphate-citrate buffer ( $\mathrm{pH}$ 5.0) containing $3.5 \times 10^{-3} \mathrm{~mol} \mathrm{~L}^{-1} \mathrm{H}_{2} \mathrm{O}_{2}$ and $5.0 \times 10^{-4} \mathrm{~mol} \mathrm{~L}^{-1} 5$-ASA in the absence (a) and presence (b) of $0.1 \mathrm{mg} \mathrm{mL}^{-1} \mathrm{HRP}$ solution. Inset: current intensities obtained at different HRP concentrations immobilized on the PGE/sol-gel at $-0.08 \mathrm{~V}$.

the resulting product from the enzymatic reaction can be reduced on the electrode surface, with maximum cathodic current intensity at $-0.08 \mathrm{~V}$. Thus, this potential was chosen for the conduct of subsequent amperometric experiments for monitoring the enzymatic reaction.

Amperometric measurements were performed by varying the HRP concentration immobilized on the sol-gel film-modified PGE (inset Figure 4). Considering the high current intensity obtained for the concentration of $0.6 \mathrm{mg} \mathrm{mL}^{-1} \mathrm{HRP}$ solution, this concentration was chosen for conducting subsequent experiments.

\section{Optimization of HRP immobilization by full factorial design}

The experimental conditions involved in the HRP immobilization were evaluated through a two-level-threefactor $\left(2^{3}\right)$ full factorial design. The effects of low and high levels on the analytical signal $(-\mathrm{I} / \mu \mathrm{A})$ are presented as plot of main effects (Figure 5a). In this figure (Figure 5a), one can see that the more intense the slope of the line, the greater the magnitude of the main effect. Figure 5a also

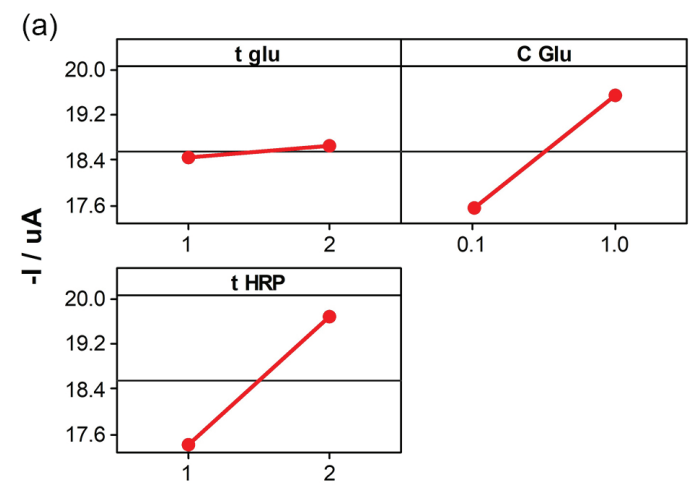

shows that $\mathrm{t}_{\mathrm{HRP}}$ and $\mathrm{C}_{\mathrm{glu}}$ had a strong positive effect on the system, with the increase of the cathodic current intensity after changing from the low level to the high level, while $\mathrm{t}_{\mathrm{glu}}$ exhibited a weak positive effect.

The HRP incubation time is expected to exert a significant influence over the signal, since the current intensity depends primarily on the amount of enzyme immobilized on the PGE surface. The strong positive effect observed for $\mathrm{t}_{\mathrm{HRP}}$ indicated that the longer incubation time allowed the effective immobilization of a higher amount of HRP on the electrode, leading to a higher signal. The significant influence of $\mathrm{C}_{\mathrm{glu}}$ was also directly associated with the amount of HRP immobilized on the PGE, since this reagent was responsible for promoting the crosslink binding between the enzyme and the electrode containing the $\mathrm{TiO}_{2}$ layer. Aldehydes are expected to form Schiff bases upon nucleophilic attack by the $\varepsilon$-amino groups of lysine residues in the protein. The linkage formed by the reaction of glutaraldehyde with an amino group has shown exceptional stability at extreme $\mathrm{pHs}$ and temperatures. ${ }^{61}$ The higher signal observed along with the higher $\mathrm{C}_{\text {glu }}$ shows that, presumably, more HRP can be immobilized on the PGE surface when additional glutaraldehyde molecules are available for reaction. By contrast, the weak influence of $t_{\text {glu }}$ on the signal indicates that the small glutaraldehyde molecules can rapidly be bound to the hydrophilic sol-gel surface $;^{62}$ and the adoption of longer periods of time in this step does not lead to a higher analytical signal. In view of that, the shorter time was chosen for $t_{\mathrm{glu}}$ in order to decrease the total amount of time for HRP immobilization.

The cube plot, shown in Figure 5b, is another way of visualizing the impact of the factors on the response. In this plot, one can observe that the use of the optimum experimental conditions $\left(\mathrm{C}_{\mathrm{glu}}=1 \% ; \mathrm{t}_{\mathrm{glu}}=1 \mathrm{~h}\right.$ and $\left.\mathrm{t}_{\mathrm{HRP}}=2 \mathrm{~h}\right)$ led to a significant increase in the signal in comparison to other combined sets of conditions, considering the same amount of analyte and substrate in solution. This same figure (Figure 5b) also showed that while the following combined

(b)

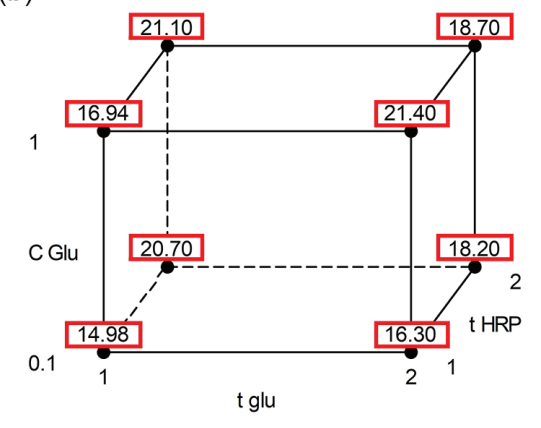

Figure 5. Plot of main effects (a) for the factors evaluated in HRP immobilization; and cube plot (b) showing the relationship between the factors and the response $(-\mathrm{I} / \mu \mathrm{A})$, highlighted at the vertices of the cube. 
set of conditions $\left(\mathrm{C}_{\mathrm{glu}}=1 \%\right.$; $\mathrm{t}_{\mathrm{glu}}=2 \mathrm{~h}$ and $\left.\mathrm{t}_{\mathrm{HRP}}=2 \mathrm{~h}\right)$ could also lead to the enhancement of the signal, one would require an additional one hour of treatment. Taking these observations into account, the repeatability of ten independently prepared electrodes was evaluated using the optimum conditions for HRP immobilization. The repeatability test yielded a satisfactory relative standard deviation (RSD) of 4.9\%, indicating a good degree of reproducibility of the method developed for HRP immobilization.

Analytical performance of the modified PGE and its application for 5-ASA determination in commercial pharmaceutical formulations

An investigation was carried out regarding the analytical performance of the modified PGE used for the determination of 5-ASA in solution. Amperometric measurements were performed in $0.1 \mathrm{~mol} \mathrm{~L}^{-1}$ citratephosphate buffer solution ( $\mathrm{pH}$ 5.0) containing $3.5 \times 10^{-3} \mathrm{~mol} \mathrm{~L}^{-1} \mathrm{H}_{2} \mathrm{O}_{2}$ and different concentrations of 5 -ASA standard solution. The cathodic current intensity measured at $-0.08 \mathrm{~V}$ presented a linear relationship with the 5-ASA (mediator) concentration. A 5-ASA analytical curve was constructed in the concentration range of $1.0 \times 10^{-5}$ to $10.0 \times 10^{-5} \mathrm{~mol} \mathrm{~L}^{-1}$ (Figure 6a). The linear regression equation of the analytical curve was $\mathrm{I}=-(0.53 \pm 0.10) \mu \mathrm{A}-(1.00 \pm 0.02) \mu \mathrm{A} \mathrm{L} \mathrm{mol}{ }^{-1}[5-\mathrm{ASA}]$, and the correlation coefficient ( $\mathrm{r}$ ) obtained was 0.9978 . The LOD and LOQ values obtained were 3.3 and $10.0 \mu \mathrm{mol} \mathrm{L}^{-1}$, respectively. Analytical experiments were also carried out in order to determine the recovery rates of the method; in this analysis, $5.0 \times 10^{-5}$ and $8.0 \times 10^{-5} \mathrm{~mol} \mathrm{~L}^{-1}$ concentration solutions of 5-ASA were tested and the corresponding current intensities were directly interpolated in the linear regression equation of the analytical curve. Satisfactory recovery rates of 96.4 and $99.8 \%$ were obtained for the tested concentrations, respectively.

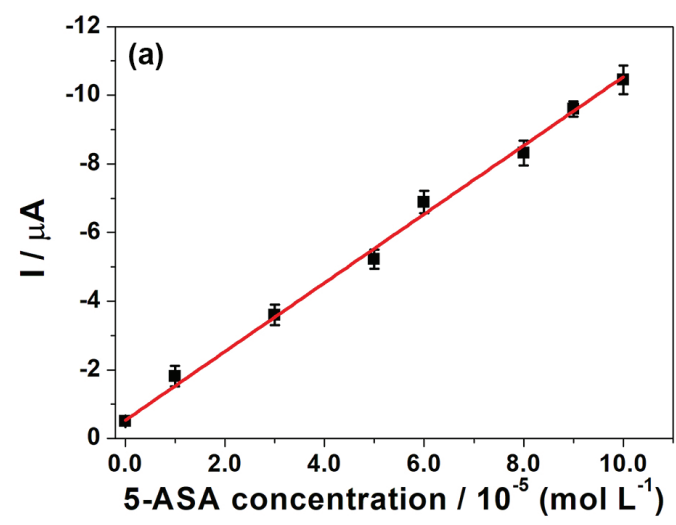

The methodology proposed in this work was applied for 5-ASA determination in commercial medicinal tablets and enemas. Aliquots of the sample solution were transferred to the electrochemical cell and the amperograms were recorded. The final concentration of the analyte was $5.0 \times 10^{-5} \mathrm{~mol} \mathrm{~L}^{-1}$ for all tested samples. Initially, the current intensities obtained from the sample analysis were directly interpolated in the analytical curve. However, the 5-ASA concentrations obtained by this procedure were in disagreement with the concentrations found in the drug labels; this may be attributed to a matrix effect on the 5-ASA amperometric responses. In this way, the standard addition method was used for the quantitative determination of 5-ASA. Figure $6 \mathrm{~b}$ presents the standard addition curve for 5-ASA determination in tablet A, by successive additions of 5-ASA standard solutions to the sample solution. The results obtained for all the samples investigated are presented in Table 2.

Table 2. 5-ASA determination in commercial pharmaceutical formulations using the HRP biosensor

\begin{tabular}{lccc}
\hline Sample & $\begin{array}{c}\text { Value in } \\
\text { the label /g }\end{array}$ & Value obtained / g & Recovered / \% \\
\hline Tablet A & 0.400 & $0.39 \pm 0.01$ & 98 \\
Tablet B & 0.400 & $0.30 \pm 0.08$ & 80 \\
Enema & 3.00 & $2.88 \pm 0.12$ & 96 \\
\hline
\end{tabular}

A comparison of the analytical performance of the methodology presented in this work with the one proposed by Uliana et al. ${ }^{50}$ shows that the LOD and LOQ values obtained in the former were higher than those obtained in the latter; this can be explained by the higher sensitivity of the square wave voltammetry technique. However, it is worth pointing out that the degree of sensitivity obtained for the sensor proposed in the present work is completely suitable for 5-ASA determination in commercial pharmaceutical formulations, given the usual content of

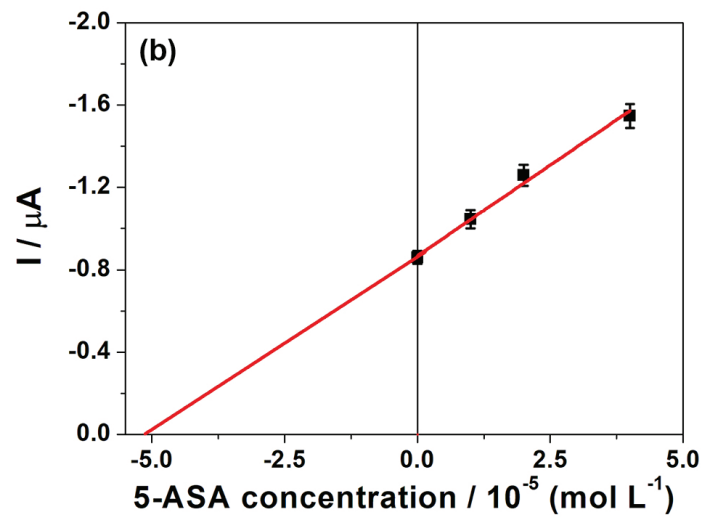

Figure 6. (a) Analytical curve for the determination of 5-ASA in the concentration range of $1.0 \times 10^{-5}$ to $10.0 \times 10^{-5} \mathrm{~mol} \mathrm{~L}^{-1}$ and (b). Standard addition curve for 5-ASA determination in a commercial pharmaceutical formulation sample (tablet A). 
the compound in these formulations. The recovery rates obtained in both methodologies were found to be similar. According to the Brazilian Pharmacopeia, the acceptable weight variation limit for any solid tablets and enemas containing over $0.250 \mathrm{~g}$ of the drug is $\pm 5.0 \% .{ }^{57}$ In this case, the samples analyzed using both methodologies are strictly in line with the Brazilian regulatory guidelines for these formulations, with the only exception being tablet B. The further comparison of the analytical performance of the presented methodology with another reported works using HRP enzyme in the development of biosensors to the determination of different oxidizable drugs (resorcinol, epinephrine, pyrogallol, pyrocatecthol, acetaminophen and clozapine) showed similar repeatability and sensitivity (limits of detection in the same order of magnitude found in this work), which confirms the potential of HRP-based biosensors to perform fast, accurate and low cost drugs determination. ${ }^{63,64}$

\section{Conclusions}

The present work reported the development of an effective methodology for HRP immobilization which involved the deposition of a $\mathrm{TiO}_{2}$ sol-gel film on the surface of PGE. The immobilization approach adopted was found to be effective in the sense that it helped preserve the HRP activity, while facilitating the electron transfer between the mediator molecule and the electrode. The optimization of the experimental conditions in the HRP immobilization procedure led to a significant enhancement of the sensor signal, thus improving the sensitivity of the method. The modified electrode was successfully applied for 5-ASA determination in commercial pharmaceutical formulations, which presented satisfactory recovery rates comparable to previously reported methodologies. The biosensor developed in this work is simple and cheap, and it is designed to be disposable. Based on the findings of this study, one can conclude that the sensor has potential to be applied for the determination of other pharmaceutical compounds which also act as electron mediators in the catalytic cycle of HRP.

\section{Acknowledgments}

The authors are grateful for the financial support granted by the National Council for Scientific and Technological Development (process CNPq 465571/2014-0), Coordination of Superior Level Staff Improvement (process CAPES 88887136426/2017/00) and the São Paulo Research Foundation (process FAPESP 2014/50945-4 and 2008/08990-1) in the development of this research.

\section{References}

1. Freire, R. S.; Pessoa, C. A.; Mello, L. D.; Kubota, L. T.; J. Braz. Chem. Soc. 2003, 14, 230.

2. Liu, S.; Huang, B.; Zheng, G.; Zhang, P.; Li, J.; Yang, B.; Chen, Y.; Liang, L.; Int. J. Biol. Macromol. 2020, 150, 814.

3. Abdulaal, W. H.; Almulaiky, Y. Q.; El-Shishtawy, R. M.; Catalysts 2020, 10, 181.

4. Zhang, C.; Li, H.; Li, C.; Li, Z.; Molecules 2020, 25, 168.

5. Yao, L.; Zheng, L.; Cai, G.; Wang, S.; Wang, L.; Lin, J.; Sensors 2020, 20, 2738.

6. Lopes, G. R.; Pinto, D. C. G. A.; Silva, A. M. S.; RSC $A d v$. 2014, 4, 37244.

7. Kandimalla, V.; Tripathi, V. S.; Ju, H.; Crit. Rev. Anal. Chem. 2006, 36, 73.

8. Gao, F.; Yuan, R.; Chai, Y.; Chen, S.; Cao, S.; Tang, M.; J. Biochem. Biophys. Methods 2007, 70, 407.

9. Chen, X.; Chen, Z.; Zhu, J.; Xu, C.; Yan, W.; Yao, C.; Bioelectrochemistry 2011, 82, 87.

10. Li, M.; Wu, J.; Su, H.; Tu, Y.; Shang, Y.; He, Y.; Liu, H.; Sensors 2019, 19, 640.

11. Ortiz, E.; Gallay, P.; Galicia, L.; Eguílaz, M.; Rivas, G.; Sens. Actuators, B 2019, 292, 254.

12. Zhang, Y.; Yuan, R.; Chai, Y.; Xiang, Y.; Hong, C.; Ran, X.; Biochem. Eng. J. 2010, 51, 102.

13. Yang, H.; Gong, C.; Miao, L.; Xu, F.; Int. J. Electrochem. Sci. 2017, 12, 4958.

14. Kafi, A. K. M.; Naqshabandi, M.; Yusoff, M. M.; Crossley, M. J.; Enzyme Microb. Technol. 2018, 113, 67.

15. Mendes, R. K.; Carvalhal, R. F.; Kubota, L. T.; J. Electroanal. Chem. 2008, 612, 164.

16. Dai, M.; Huang, T.; Chao, L.; Xie, Q.; Tan, Y.; Chen, C.; Meng, W.; Talanta 2016, 149, 117.

17. Fallah, M.; Rahimnejad, M.; Asghary, M.; Mashkour, M.; Anal. Methods 2019, 12, 33.

18. Raghu, P.; Reddy, T. M.; Gopal, P.; Reddaiah, K.; Sreedhar, N. Y.; Enzyme Microb. Technol. 2014, 57, 8.

19. Ding, C.; Zhao, F.; Ren, R.; Lin, J. M.; Talanta 2009, 78, 1148.

20. Spychalska, K.; Zając, D.; Cabaj, J.; RSC Adv. 2020, $10,9079$.

21. Baluta, S.; Zając, D.; Szyszka, A.; Malecha, K.; Cabaj, J.; Sensors 2020, 20, 423.

22. Al-Ahmed, A.; Ndangili, P. M.; Jahed, N.; Baker, P. G. L.; Iwuoha, E. I.; Sensors 2009, 9, 9965.

23. Wang, J.; Kawde, A. N.; Anal. Chim. Acta 2001, 431, 219.

24. Aoki, K.; Okamoto, T.; Kaneko, H.; Nozaki, K.; Negishi, A.; J. Electroanal. Chem. 1989, 263, 323.

25. Nathani, A.; Vishnu, N.; Sharma, C. S.; J. Electrochem. Soc. 2020, 167, 037520.

26. Cam, E.; Tanik, N. A.; Cerkez, I.; Demirkan, E.; Aykut, Y.; J. Appl. Polym. Sci. 2018, 135, 45567.

27. Erdem, A.; Congur, G.; Electroanalysis 2018, 30, 67. 
28. Ensafi, A. A.; Jamei, H. R.; Heydari-Bafrooei, E.; Rezaei, B.; Bioelectrochemistry 2016, 111, 15.

29. Vural, T.; Yaman, Y. T.; Ozturk, S.; Abaci, S.; Denkbas, E. B.; J. Colloid Interface Sci. 2018, 510, 318.

30. Güner, A.; Çevik, E.; Şenel, M.; Alpsoy, L.; Food Chem. 2017, $229,358$.

31. Engel, L.; Baumann, W.; Fresenius' J. Anal. Chem. 1993, 346, 745 .

32. Sahyar, B. Y.; Kaplan, M.; Ozsoz, M.; Celik, E.; Otles, S.; Bioelectrochemistry 2019, 130, 107327.

33. Rewatkar, P.; Bandapati, M.; Goel, S.; Int. J. Hydrogen Energy 2019, 44, 31434.

34. Sharma, M.; Yadav, P.; Sharma, M.; Carbohydr. Res. 2019, 483, 107749.

35. Moyo, M.; Okonkwo, J. O.; Agyei, N. M.; Enzyme Microb. Technol. 2014, 56, 28.

36. Li, Z. L.; Cheng, L.; Zhang, L. W.; Liu, W.; Ma, W. Q.; Liu, L.; Process Saf. Environ. Prot. 2017, 107, 463.

37. Zeng, Y.; Zheng, A.; Wu, J.; Cai, Z.; Huang, A.; Liu, X.; Anal. Chim. Acta 2015, 899, 100.

38. Wang, F.; Gong, W.; Wang, L.; Chen, Z.; Microchim. Acta 2015 , $182,1949$.

39. Wang, J.; Anal. Chim. Acta 1999, 399, 21.

40. Gupta, R.; Chaudhury, N. K.; Biosens. Bioelectron. 2007, 22, 2387.

41. Jia, J.; Wang, B.; Wu, A.; Cheng, G.; Li, Z.; Dong, S.; Anal. Chem. 2002, 74, 2217.

42. Hu, H.; Wang, B.; Li, Y.; Wang, P.; Yang, L.; Electroanalysis 2020, 32, 60027.

43. Cui, H. F.; Wu, W. W.; Li, M. M.; Song, X.; Lv, Y.; Zhang, T. T.; Biosens. Bioelectron. 2018, 99, 223.

44. Doong, R.; Shih, H.; Biosens. Bioelectron. 2006, 22, 185.

45. Chen, X.; Cheng, G.; Dong, S.; Analyst 2001, 126, 1728.

46. Chen, X.; Dong, S.; Biosens. Bioelectron. 2003, 18, 999.

47. Gotti, R.; Pomponio, R.; Bertucci, C.; Cavrini, V.; J. Chromatogr. A 2001, 916, 175.
48. Bystrowska, B.; Nowak, J.; Brandys, J.; J. Pharm. Biomed. Anal. 2000, 22, 341.

49. Nobilis, M.; Vybíralová, Z.; Sládková, K.; Lísa, M.; Holcapek, M.; Kvetina, J.; J. Chromatogr. A 2006, 1119, 299.

50. Uliana, C. V.; Yamanaka, H.; Garbellini, G. S.; Salazar-Banda, G. R.; Quim. Nova 2010, 33, 964.

51. Uliana, C. V.; Riccardi, C. S.; Yamanaka, H.; Ecletica Quim. 2008, 33, 57.

52. Zanoni, M. V. B.; Sene, J. J.; Anderson, M. A.; J. Photochem. Photobiol., A 2003, 157, 55.

53. Xu, Q.; Anderson, M. A.; J. Mater. Res. 1991, 6, 1073.

54. Minitab 15; Minitab Inc., State College, PA, USA, 2013.

55. Brereton, R. G.; Chemometrics: Data Analysis for the Laboratory and Chemical Plant, $1^{\text {st }}$ ed.; Wiley: Chichester, 2003.

56. Uliana, C. V.; Tognolli, J. O.; Yamanaka, H.; Electroanalysis 2011, 23, 2607.

57. Farmacopeia Brasileira, $6^{\text {th }}$ ed.; Agência Nacional de Vigilância Sanitária (ANVISA): Brasília, 2019.

58. Fabregat-Santiago, F.; Mora-Seró, I.; Garcia-Belmonte, G.; Bisquert, J.; J. Phys. Chem. B 2003, 107, 758.

59. Marken, F.; Bhambra, A. S.; Kim, D. H.; Mortimer, R. J.; Stott, S. J.; Electrochem. Commun. 2004, 6, 1153.

60. Vadgama, P.; Crump, P. W.; Analyst 1992, 117, 1657.

61. Migneault, I.; Dartiguenave, C.; Bertrand, M. J.; Waldron, K. C.; BioTechniques 2004, 37, 790.

62. Wang, X.; Chen, Z.; Li, K.; Wei, X.; Chen, Z.; Ruso, J. M.; Tang, Z.; Liu, Z.; Colloids Surf., A 2019, 560, 298.

63. Erdem, A.; Pabuccuoglu, A.; Merüc, B.; Kerman, K.; Ozsoz, M.; Turk. J. Med. Sci. 2000, 30, 349.

64. Yu, D.; Blankert, B.; Kauffmann, J.; Biosens. Bioelectron. 2007, 22, 2707.

Submitted: December 3, 2020

Published online: February 12, 2021 